\title{
PERBANDINGAN HASIL BELAJAR MATEMATIKA ANTARA YANG MENGGUNAKAN PENDEKATAN KONSTRUKTIVISME DENGAN PENDEKATAN OPEN ENDED
}

\author{
Avini Nurazhimah Arfa \\ Program Studi Informatika, Universitas Indraprasta PGRI \\ Email: avininurazh@gmail.com
}

\begin{abstract}
Abstrak
Penelitian ini bertujuan untuk mengetahui ada atau tidaknya perbandingan Hasil Belajar siswa kelas X TKJ 1 dan X TKJ 2 antara yang menggunakan pendekatan konstruktivisme dan open ended dalam pembelajaran mata pelajaran matematika pada bab statistika. Metode penelitian yang dipakai adalah kuasi eksprerimen dengan populasi penelitian adalah siswa SMK TERPADU HUTAMA, sedangkan sampel penelitian diambil secara acak sederhana sebanyak 68 orang menggunakan instrumen yang dikembangkan sendiri berbentuk tes tentang Hasil Belajar Matematika. Data hasil penelitian untuk kelas eksperimen maupun kontrol yang dijaring dengan tes dianalisis dengan uji $t$, sedangkan uji persyaratan analisis normalitas dengan uji chi-kuadrat dan homogenitas dengan uji $F$. Hasil penelitian menemukan bahwa terdapat perbandingan yang bermakna antara Hasil Belajar siswa melalui pendekatan konstruktivisme dan melalui pendekatan open ended pada pembelajaran matematika siswa-siswi SMK TERPADU HUTAMA. Dari hasil penelitian dapat disimpulkan, pendekatan konstruktivisme lebih baik dibandingkan pendekatan open onded dalam pembelajaran statistika karena dapat mendorong pengembangan individu di kelas.
\end{abstract}

Kata Kunci : Pembelajaran Konstruktivisme, Pembelajaran Open ended, Hasil Belajar, Pembelajaran Matematika

\begin{abstract}
The purpose of this research is to know whether or not there are differences of learning outcomes of students of class X TKJ 1 and X TKJ 2 between those using a constructivism approach and those using an open-ended approach in learning mathematics in statistics chapter. The research method used is a quasi-experiment with population of students of SMK TERPADU HUTAMA and with samples of 68 people simply and randomly taken by using a self-developed instrument in the form of test about Mathematics Learning Outcomes. The research data for the experimental and controlled classes are collected by analyzing the test using $t$ test, while the normality analysis requirement is analyzed by testing with chi-square test and homogeneity with $F$ test. The result of the research shows that there is a significant difference between students' learning outcomes through constructivism approach and through an open-ended approach to mathematics learning in SMK TERPADU HUTAMA. From the research results, it can be concluded that the constructivism approach is better than the open-ended approach in statistics learning because the former can encourage the development of individual's skill in the classroom.
\end{abstract}

Keywords: Constructivism Learning, Open ended Learning, Learning Outcomes, Mathematics Learning

\section{PENDAHULUAN}

Melalui belajar matematika diharapkan para siswa bisa mendapatkan kemampuan yang terlihat melalui cara berpikir yang sistematis, obyektif, kritis, jujur dan disiplin. Namun dalam kenyataannya, pendidikan di Indonesia banyak mengalami hambatan. Hambatan tersebut antara lain: kurikulum yang selalu berubah-ubah dalam waktu yang singkat, mutu pendidikan yang kurang begitu bagus, distribusi guru yang kurang memadai, tempat belajar yang masih terbatas di kelas maupun di sekolahan dan juga lingkungan belajar, keluarga, serta masyarakat yang kurang mendukung. Pembelajaran adalah sebuah proses yang cukup rumit karena tidak hanya mendapat 
informasi dari guru akan tetapi melibatkan banyak kegiatan dan tindakan yang harus dilakukan untuk memperoleh hasil belajar yang lebih baik. Salah satunya adalah sebuah kegiatan belajar yang menitikberatkan pada kegiatan dan tindakan yaitu menggunakan metode tertentu dalam pembelajaran tersebut. Metode dalam pembelajaran merupakan cara yang dipakai guru, dalam menjalankan kewajibannya yang merupakan alat untuk mencapai tujuan pembelajaran [1].

Hal lain yang tidak bisa dielakkan bahwa proses pembelajaran matematika di sekolah kurang disukai oleh siswa. Di dalam kelas rata-rata banyak siswa yang tidak semangat dalam mengikuti proses belajar matematika. Terlihat dari adanya yang mengobrol dengan teman, seringnya keluar masuk kelas, melakukan kegiatan di luar pelajaran (matematika) dan sedikit yang memang serius mengikuti apa yang dijelaskan oleh guru. Dari pengalaman peneliti yang pernah terjun menjadi guru les privat, ada beberapa anak mengeluh saat belajar matematika dan merasa kurang mengerti dengan pelajaran matematika karena tidak merasa ada manfaatnya di kehidupan nyata. Dan ada juga siswa yang menjawab soal matematika dengan hanya melihat contoh soal yang sudah ada dalam buku tanpa memperhatikan prosesnya. Karena banyaknya siswa yang masih kurang paham akan pelajaran matematika, maka berimbas pada hasil UN Matematika. Berikut peneliti dapatkan data kurangnya hasil UN MTK yang rendah dari mata pelajaran lain.

Tabel 1 Nilai Rata-Rata UN dalam Kurun Waktu 2009-2011

\begin{tabular}{llccc}
\hline No & $\begin{array}{c}\text { Mata } \\
\text { Pelajaran }\end{array}$ & $\begin{array}{c}\mathbf{2 0 0 8}- \\
\mathbf{2 0 0 9}\end{array}$ & $\begin{array}{c}\mathbf{2 0 0 9}- \\
\mathbf{2 0 1 0}\end{array}$ & $\begin{array}{c}\mathbf{2 0 1 0}- \\
\mathbf{2 0 1 1}\end{array}$ \\
\hline 1. & Bahasa & 8,50 & 6,85 & 7,52 \\
& Indonesia & & & \\
2. & Matematika & 7,40 & 6,25 & 6,61 \\
3. & Bahasa Inggris & 8,30 & 6,80 & 7,31 \\
\hline
\end{tabular}

(Sumber : SMK DKI.net) Peneliti berusaha untuk meningkatkan nilai UN MTK agar tidak rendah, yaitu dengan menerapkan sistem pembelajaran di tempat peneliti berlangsung. Sebagai solusi mengatasi kurangnya minat dalam belajar matematika, maka peneliti mencoba menggunakan metode pembelajaran dengan menggunakan pendekatan konstruktivisme dan pendekatan openended yang dapat diaplikasikan dalam mengantisipasi masalah yang timbul selama proses pembelajaran matematika, khususnya materi Statistika, agar ada perubahan dalam pembelajaran matematika. Maka dari itu peneliti melakukan penelitian Perbandingan Hasil Belajar Matematika antara yang menggunakan Pendekatan Konstruktivisme dan Pendekatan Open-ended. Sehingga kiranya hasil penelitian ini dapat digunakan sebagai bahan referensi untuk penelitian lanjutan, dengan tema yang sama akan tetapi dengan metode, teknik analisa atau mungkin populasi dan sampel yang berbeda, sehingga dapat dilakukan proses verifikasi demi kemajuan ilmu pengetahuan, khususnya untuk perbaikan kualitas pendidikan di Indonesia.

\section{Pendekatan Kontruktivisme}

Pembelajaran berdasarkan pandangan konstruktivisme adalah suatu cara membangun pengetahuan baru dalam struktur kognitif siswa yang didasarkan pada pengalamannya. Menurut paham konstruktivisme, pengetahuan itu benar berasal dari luar tetapi dikonstruksi oleh dan dari dalam diri seseorang. Pengetahuan terbentuk dari dua faktor penting, pertama objek yang menjadi pengamatan dan kedua kemampuan subjek untuk menjabarkan objek tersebut. Kedua faktor itu sama pentingnya. Dengan demikian, pengetahuan itu tidak bersifat diam akan tetapi bersifat bergerak, tergantung pada individu yang melihat dan mengkonstruksinya [2]. 
Teori pembelajaran konstruktivisme mempunyai dampak baik terhadap pembelajaran matematika, yaitu membantu siswa untuk membuat konsep matematika dengan kemampuannya sendiri melalui internalisasi, sehingga konsep itu terbangun kembali melalui transformasi informasi untuk menjadi konsep baru [3]. Sehingga dapat dikatakan bahwa pembelajaran matematika adalah membangun pemahaman.

Belajar dilihat sebagai proses aktif dan konstruktif dimana para siswa dilatih menyelesaikan masalah yang muncul. Dengan pendekatan konstruktivisme dalam pembelajaran matematika, siswa diharapkan bisa ikut aktif untuk mengembangkan kemampuannya baik dalam hal mengingat materi, mengamati, memahami, dan mengaplikasikan konsep, sehingga melalui proses itu suswa dapat membangun sendiri pengetahuan baru.

Guru harus bisa mengusahakan sistem pembelajaran sehingga dalam pembelajaran siswa dapat menguasai pelajaran dan mencapai hasil secara optimal. Berdasarkan keterangan tersebut, jelas terlihat bahwa dalam pembelajaran konstruktivisme, siswa yang dituntut lebih banyak aktif untuk dapat mengkonstruksi pengetahuannya, sedangkan tugas seorang guru adalah mengarahkan siswanya dalam mengkonstruksi pengetahuan sehingga diperoleh konsep matematika. Yang berarti siswa harus bisa membangun pengetahuan mereka sendiri, dan guru dapat memberikan kesempatan kepada siswa untuk menemukan atau menerapkan idenya dan mengajak siswa menggunakan strategi mereka sendiri untuk belajar. Tugas pendidik tidak hanya menuangkan sejumlah informasi ke dalam benak siswa, tetapi mengusahakan bagaimana agar konsep-konsep penting dan sangat berguna tertanam kuat dalam benak siswa [4].

\section{Pendekatan Open Ended}

Masalah yang diformulasikan memiliki banyak jawaban yang benar disebut problem tak lengkap atau juga open-ended problem atau soal terbuka [5]. Siswa yang dihadapkan dengan masalah ini, tujuannya bukan untuk mendapatkan jawaban tetapi menekankan kepada cara bagaimana siswa tersebut sampai pada suatu jawaban.

Contoh penerapan masalah open-ended adalah ketika siswa diminta untuk mengembangkan sebuah metode, cara atau pendekatan yang berbeda dalam menjawab permasalahan yang diberikan dan tidak terfokus pada jawaban (hasil) akhir. Pembelajaran dengan metode ini diawali dengan memberikan masalah terbuka kepada siswa. Kegiatan belajarnyapun harus diarahkan dan bisa membawa siswa untuk menjawab masalah dengan banyak cara atau mungkin juga dengan banyak jawaban (yang benar), sehingga merangsang kemampuan intelektual dan pengalaman siswa dalam menemukan sesuatu yang baru. Tujuan dari pembelajaran open ended ialah untuk membantu mengembangkan kegiatan kreatif dan cara berpikir matematik siswa melalui problem posing secara terus menerus [5]. Dengan kata lain, kegiatan kreatif dan cara berpikir matematik siswa harus dikembangkan semaksimal mungkin sesuai dengan kemampuan yang dimiliki setiap siswa. Inilah yang menjadi pokok utama pembelajaran open ended, yaitu pembelajaran yang membangun sebuah kegiatan interaktif antara matematika dan siswa sehingga membuat siswa untuk menjawab permasalahan melalui berbagai strategi. Oleh karena itu, hal yang perlu diperhatikan adalah kebebasan siswa untuk berpikir dalam membuat kemajuan pemecahan sesuai dengan kemampuan, sikap, dan minatnya sehingga pada akhirnya akan membentuk intelegensi matematika siswa. 


\section{METODE}

Penelitian ini dilaksanakan di Sekolah Menengah Kejuruan (SMK) TERPADU HUTAMA yang beralamat di Jl. Raya Hankam no. 37 Pondok Melati, JakartaTimur, yang dipimpin oleh Bapak Drs. Asep Hidayat Aziz, SmHK. S.Pd. MM dengan jumlah seluruh guru 48 orang dan memiliki 15 rombongan belajar. Berikut adalah tabel data jumlah siswa SMK Terpadu Hutama:

\section{Tabel 2 Jumlah Siswa SMK Terpadu Hutama Jakarta Timur}

\begin{tabular}{|c|c|c|c|c|c|c|c|c|c|}
\hline \multirow{2}{*}{ Kelas } & \multicolumn{3}{|c|}{ Kelas X } & \multicolumn{3}{|c|}{ Kelas XI } & \multicolumn{3}{|c|}{ Kelas XII } \\
\hline & L & $\mathrm{P}$ & $\sum$ & L & $\mathrm{P}$ & $\Sigma$ & $\mathrm{L}$ & $\mathrm{P}$ & $\sum$ \\
\hline TKJ 1 & 27 & 7 & 34 & 25 & 9 & 34 & 25 & 9 & 34 \\
\hline TKJ 2 & 29 & 5 & 34 & 22 & 12 & 34 & 24 & 8 & 32 \\
\hline TKJ 3 & 28 & 6 & 34 & 23 & 11 & 34 & 26 & 8 & 34 \\
\hline BDC 1 & 15 & 19 & 34 & 16 & 18 & 34 & 16 & 18 & 34 \\
\hline BDC 2 & 12 & 22 & 34 & 18 & 16 & 34 & 15 & 19 & 34 \\
\hline Jumlah & 111 & 59 & 168 & 104 & 66 & 170 & 106 & 62 & 168 \\
\hline $\begin{array}{l}\text { Total } \\
\text { Siswa }\end{array}$ & & & & & 508 & & & & \\
\hline
\end{tabular}

Penelitian ini berlangsung selama 6 bulan, yaitu mulai bulan April hingga September tahun pelajaran 2012/2013. Dalam pelaksanaannya dibagi ke dalam 3 tahap, yaitu tahap persiapan, tahap pengumpulan data dan tahap pengolahan data.

Metode yang digunakan dalam penelitian ini adalah metode quasi eksperimen. Hasil belajar yang merupakan data dari penelitian ini dikelompokkan menjadi dua yaitu: Hasil belajar matematika kelompok siswa yang diajar dengan metode pembelajaran pendekatan konstruktivisme, dan hasil belajar matematika kelompok siswa yang diajar dengan metode pembelajaran pendekatan open-ended. Hasil belajar tersebut diambil dari tes materi pelajaran yang dipakai untuk eksperimen yaitu mencakup pokok bahasan statistika. Sebagai variabel terikat adalah hasil belajar matematika siswa dan sebagai variabel bebas adalah metode pembelajaran pendekatan konstruktivisme dan metode pembelajaran pendekatan open-ended. Rancangan penelitian tersebut dinyatakan sebagai berikut:

Tabel 3. Rancangan Penelitian

\begin{tabular}{ccc}
\hline Kelompok & Variabel & Pasca Tes \\
\hline (R) E & $\mathrm{X}_{\mathrm{E}}$ & $\mathrm{Y}_{2}$ \\
$(\mathrm{R}) \mathrm{C}$ & $\mathrm{X}_{\mathrm{C}}$ & $\mathrm{Y}_{2}$ \\
\hline
\end{tabular}

Keterangan:

E : Kelompok Eksperimen

C : Kelompok Kontrol

$\mathrm{X}_{\mathrm{E}}$ : Perlakuan yang diberikan pada kelompok eksperimen

$\mathrm{X}_{\mathrm{C}}$ : Perlakuan yang diberikan pada kelompok kontrol

$\mathrm{Y}_{2}$ : Tes akhir yang sama pada kedua kelompok

$\mathrm{R}$ : Proses pemilihan subyek secara random

\section{HASIL DAN PEMBAHASAN}

Berdasarkan hasil penelitian yang dilakukan diperoleh rangkuman data sebagai berikut:

Tabel 4. Deskripsi Data Hasil Penelitian

\begin{tabular}{lcc}
\hline \multicolumn{1}{c}{ Deskripsi } & $\begin{array}{c}\text { Kelas } \\
\text { Eksperimen }\end{array}$ & $\begin{array}{c}\text { Kelas } \\
\text { Kontrol }\end{array}$ \\
\hline Mean & 78.15 & 54.15 \\
Median & 78.22 & 52.5 \\
Modus & 78.5 & 50.4 \\
Standar Deviasi & 6.85 & 8.57 \\
Minimum & 65 & 32 \\
Maximum & 90 & 80 \\
Uji Normalitas & $1.43 \leq 11.07=$ & $1.89 \leq 11.07$ \\
& Normal & $=$ Normal \\
Uji Homogenitas & $1.56 \leq 1.74=$ Homogen \\
\hline
\end{tabular}

Berdasarkan hasil deskripsi data pada Tabel 4, ditunjukkan bahwa pada kelas eksperimen (kelas yang menggunakan pendekatan konstruktivisme) diperoleh skor terendah 65 dan skor tertinggi 90 sehingga rentangnya 25. Skor Mean = 78.15; Median = 78.22; Modus = 78.5; dan standar deviasi $=6.85$. Serta daftar distribusi frekuensi skor hasil belajar matematika dengan pendekatan konstruktivisme dapat dilihat pada tabel 7 , 
dan bila divisualisasikan dalam bentuk histogram ditunjukkan pada Gambar 1 .

Berdasarkan analisis deskripsi ditunjukkan bahwa pada kelas eksperimen (kelas yang menggunakan pendekatan konstruktivisme), responden yang memiliki hasil belajar matematika pada kelas rerata sebanyak 7 anak atau 20.588 $\%$, yang memiliki hasil belajar matematika di bawah rerata sebanyak 14 anak atau $41.176 \%$, dan yang memiliki hasil belajar matematika di atas rerata sebanyak 13 anak atau $38.235 \%$.

\section{Tabel 5 Daftar Distribusi Frekuensi} Skor Hasil Belajar Matematika dengan Pendekatan Konstruktivisme

\begin{tabular}{cccc}
\hline No & Kelas Interval & $\begin{array}{c}\text { Frek } \\
\text { Absolut }\end{array}$ & $\begin{array}{c}\text { Frek } \\
\text { Relatif }\end{array}$ \\
\hline 1. & $65-68$ & 3 & 8.823 \\
2. & $69-72$ & 5 & 14.706 \\
3. & $73-76$ & 6 & 17.647 \\
4. & $77-80$ & 7 & 29.167 \\
5. & $81-84$ & 6 & 17.647 \\
6. & $85-88$ & 5 & 14.706 \\
7. & $89-92$ & 2 & 5.882 \\
& Jumlah & 34 & 100 \\
\hline
\end{tabular}

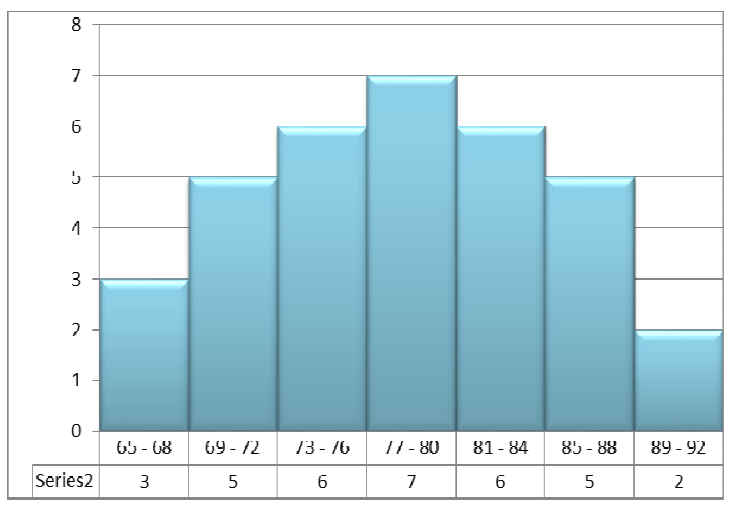

\section{Gambar 1. Histogram Hasil Belajar Matematika dengan Pendekatan Konstruktivisme}

Berdasarkan hasil deskripsi data pada tabel 4, ditunjukkan bahwa pada kelas kontrol (kelas yang menggunakan pendekatan open ended) diperoleh skor terendah 32 dan skor tertinggi 80 sehingga rentangnya 48. Skor Mean = 54.15; Median = 52.5;
Modus $=50.4 ;$ dan standar deviasi $=8.57$. Serta daftar distribusi frekuensi skor hasil belajar matematika dengan pendekatan open ended dapat dilihat pada tabel 6 , dan bila divisualisasikan dalam bentuk histogram ditunjukkan pada gambar 2 .

Berdasarkan analisis deskripsi tabel 5 dan gambar 2, ditunjukkan bahwa pada kelas kontrol (kelas yang menggunakan pendekatan open ended) responden yang memiliki hasil belajar matematika pada kelas rerata sebanyak 6 anak atau $17.647 \%$, yang memiliki hasil belajar matematika di bawah rerata sebanyak 17 anak atau $50 \%$, dan yang memiliki hasil belajar matematika di atas rerata sebanyak 11 anak atau $32.353 \%$.

\section{Tabel 6 Daftar Distribusi Frekuensi Skor \\ Hasil Belajar Matematika dengan Pendeketan Open Ended}

\begin{tabular}{cccc}
\hline No & Kelas Interval & $\begin{array}{c}\text { Frek } \\
\text { Absolut }\end{array}$ & $\begin{array}{c}\text { Frek } \\
\text { Relatif }\end{array}$ \\
\hline $\mathbf{1 .}$ & $32-38$ & 3 & 8.824 \\
$\mathbf{2 .}$ & $39-45$ & 5 & 14.706 \\
$\mathbf{3 .}$ & $46-52$ & 9 & 26.471 \\
$\mathbf{4 .}$ & $53-59$ & 6 & 17.647 \\
$\mathbf{5 .}$ & $60-66$ & 5 & 14.706 \\
$\mathbf{6 .}$ & $67-73$ & 4 & 11.765 \\
$\mathbf{7 .}$ & $74-80$ & 2 & 5.882 \\
& Jumlah & 34 & 100 \\
\hline
\end{tabular}

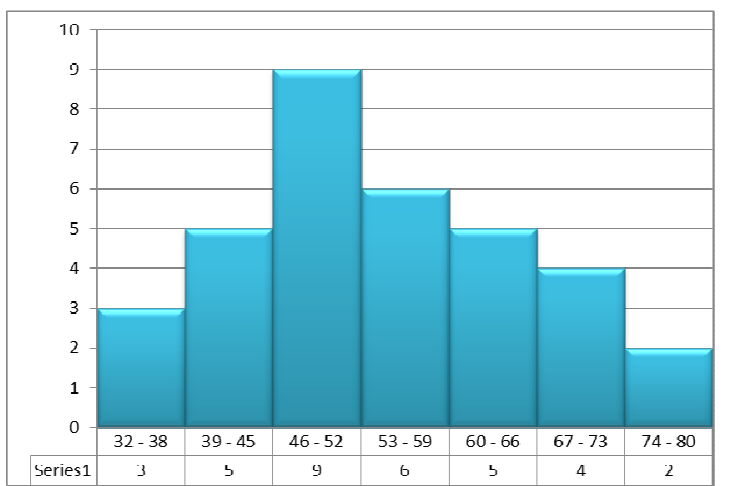

Gambar 2 Histogram Hasil Belajar Matematika dengan Pendekatan Open Ended

Pengujian normalitas pada kelas eksperimen (kelas yang menggunakan 
pendekatan konstruktivisme) dan kelas kontrol (kelas yang menggunakan pendekatan open endeed) dilakukan dengan menggunakan rumus chi-kuadrat. Data dikatakan normal jika $x^{2}$ hitung $\leq x_{\text {tabel. }}^{2}$ Berdasarkan hasil pengujian diperoleh bahwa pada kelas eksperimen (kelas yang menggunakan pendekatan konstruktivisme) $x^{2}$ hitung $=1.43$ dengan $x^{2}$ tabel untuk $n=34$ adalah 11.07. Hal ini bearti bahwa $x_{\text {hitung }}^{2}=1.43 \leq x_{\text {tabel }}{ }_{\text {tab }}=11.07$, dengan demikian data pretest kelas eksperimen adalah normal. Sedangkan pada kelas kontrol (kelas yang menggunakan pendekatan open endeed) $x^{2}$ hitung $=1.89$ dengan $x_{\text {tabel }}^{2}$ untuk $n=34$ adalah 11.07. Hal ini bearti bahwa $x^{2}$ hitung $=$ $1.89 \leq x^{2}$ tabel $=11.07$, dengan demikian data pretest kelas open endeed adalah normal. Pengujian Homogenitas juga dilakukan untuk mengetahui apakah sampel penelitian yang digunakan berasal dari populasi yang homogen atau sama. Pengujian menggunakan Uji $F$ dengan taraf signifikansi $\alpha=0.05$ dengan kriteria $F_{\text {hitung }} \leq F_{\text {tabel }}$ maka data homogen. Berdasarkan hasil perhitungan uji homogenitas terhadap varians populasi antara kelompok eksperimen dan kelompok kontrol diperoleh $F_{\text {hitung }}=1.56$ sedangkan $\quad F_{\text {tabel }}=1.74$ pada taraf signifikansi $\alpha=0.05$ dengan jumlah $d b=$ 1. Hasil ini menunjukkan $F_{\text {hitung }}=1.56 \leq$ $F_{\text {tabel }}=1.74$, berarti data tentang hasill belajar matematika kelas eksperimen dan kelas kontrol memiliki varians yang homogen, dengan demikian kedua varians tersebut bisa dibandingkan dan dilanjutkan dengan analisis data.

Pengujian hipotesis dilakukan setelah pengujian normalitas dan homogenitas dilakukan, berdasarkan teknik analisis data bahwa pengujian hipotesis dilakukan dengan uji $t$. Dari data tersebut didapat bahwa pada skot thitung $=12.79$ dan $t_{\text {tabel }}$ pada taraf signifikansi $\alpha=0.05$ adalah 1.98 , dengan demikian $t_{\text {hitung }}=12.79 \geq t_{\text {tabel }}$
$=$ 1.98. Hal ini menunjukan bahwa $\mathrm{H}_{\mathrm{o}}$ ditolak atau $\mathrm{H}_{1}=$ diterima.

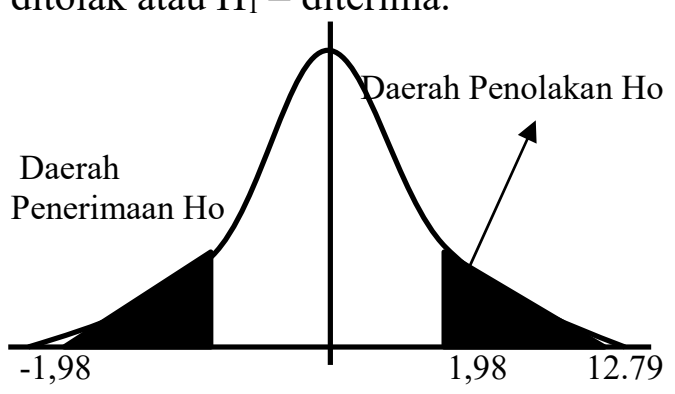

\section{Gambar 3. Kurva Penerimaan/Penolakan Ho}

Dari hasil perhitungan diperoleh bahwa $t_{\text {hitung }}>\mathrm{t}_{\text {tabel }}\left(\mathrm{t}_{\text {hitung }}\right.$ terletak di luar wilayah penerimaan $\mathrm{H}_{0}$ ). Dari fakta di atas, penelitian ini telah memperoleh jawaban bahwa terdapat perbedaan hasil belajar matematika antara siswa yang diajar dengan menggunakan metode pembelajaran konstruktivisme dengan siswa yang diajar dengan menggunakan metode pembelajaran open ended.

Hasil penelitian ini memberikan informasi bahwa dalam pembelajaran matematika pendekatan konstruktivisme lebih efektif jika dibandingkan dengan pendekatan open ended. Pembelajaran matematika pada kelas eksperimen (kelas yang menggunakan pendekatan konstruktivisme) skor hasil belajar rataratanya 78.15 lebih tinggi dari kelas kontrol (kelas yang menggunakan pendekatan open ended) yaitu rata-ratanya 54.15. Pengujian dengan uji $t$ menunjukkan $t_{\text {hitung }}$ adalah 12.79 lebih besar dari $\mathrm{t}_{\text {tabel }}$ 1.98 .

Hal ini disebabkan pembelajaran matematika dengan menggunakan pendekatan konstruktivisme menjadikan guru berperan mempromosikan dan mendorong pengembangan setiap individu di dalam kelas untuk menguatkan konstruksi dasar matematika, untuk pengajuan pertanyaan, pengeksplorasian, pemecahan, dan pembenaran masalah- 
masalah matematika serta konsep-konsep matematika dalam statistika khususnya. Di sini guru juga mengembangkan kemampuan mahasiswa merefleksikan dan mengevaluasi kualitas konstruksi siswa. Dengan kata lain, pembelajaran matematika yang menggunakan pendekatan konstruktivisme menjadikan posisi guru bernegosiasi dengan murid. Negosiasi yang dimaksudkan di sini adalah guru tidak berperan sebagai pemberi jawaban akhir atas pertanyaan siswa, tetapi mengajukan pertanyaan-pertanyaan kembali atau pertanyaan-pertanyaan yang menantang siswa untuk berpikir lebih lanjut yang dapat mendorong dan mengarahkan mereka untuk membentuk (mengkonstruksi) pengetahuan matematika sehingga diperoleh struktur matematika.

\section{SIMPULAN}

Berdasarkan temuan di atas, dapat diperoleh simpulan bahwa terdapat perbedaan yang signifikan penggunaan pendekatan konstruktivisme terhadap hasil belajar dalam pembelajaran mata pelajaran matematika bab statistika dibandingkan dengan pendekatan open ended. Artinya penggunaan pendekatan konstruktivisme lebih baik daripada pendekatan open ended dalam pembelajaran matematika bab statistika di SMK Terpadu Hutama.

\section{DAFTAR PUSTAKA}

[1] H. Uno. Model Pembelajaran: Menciptakan Proses Belajar Mengajar yang Kreatif dan Efektif. Jakarta: Bumi Aksara, 2007.

[2] W. Sanjaya. Strategi Pembelajaran, Jakarta: Kencana, 2005.

[3] M. Nur, P. R. Wikandari. Pengajaran Berpusat Kepada Siswa dan Pendekatan Konstruktivis dalam Pengajaran. Surabaya: UNESA Press, 2000.

[4] J. Confrey. What constructivism implies for teaching. Washington D.C, 1992.
[5] Suherman dan Sukjaya. Petunjuk Praktis untuk Melaksanakan Evaluasi Pendidikan Matematika. Bandung: Wijaya Kusuma, 2003 